\title{
Demographic Contributions to Policymaking during the Pandemic
}

Sonalde Desai

Follow this and additional works at: https://knowledgecommons.popcouncil.org/series_pdr_essays-covid How does access to this work benefit you? Let us know!

\section{Recommended Citation}

Desai, Sonalde. "Demographic Contributions to Policymaking during the Pandemic." In Covid-19 and the Global Demographic Research Agenda, edited by Landis MacKellar and Rachel Friedman, 28-32. New York: Population Council, 2021. 


\title{
Demographic Contributions to Policymaking during the Pandemic
}

\author{
SONALDE DESAI
}

AS DEMOGRAPHERS LOOK BACK on 2020, it seems likely that it will be with a greater appreciation for the importance of demographic data in a public health emergency, possibly coupled with some regret at missing an opportunity for making meaningful contributions to public discourse as nations struggled to cope with the pandemic. I hope this regret will translate into energizing our field to reshape the way we go about our business.

Paul Demeny (1988), in an article published in Population and Development Review, commented that demography as a discipline has long been uneasy trying to balance its role as producer of knowledge with seeing this knowledge applied in service of public policy. As we speculate about the impact of Covid-19 on the future of our discipline, it is much easier to think about how it may change our repertoire of research topics and methodologies than to reflect on whether the way our field has organized itself was conducive to public service during these difficult times.

The most significant impact of Covid-19 on demography is likely to be in the arena of data collection. Mortality data, particularly age- and cause-specific mortality data, were invaluable in estimating the seriousness of Covid-19. As the pandemic's course progressed and concerns about economic impacts began to dominate, most countries adopted more sophisticated approaches to targeting vulnerable populations. Areas in which Covid positivity rates exceeded a certain threshold were locked down; individuals in some areas and some occupations were offered social protection benefits; businesses and modes of travel with greater disease transmission possibilities were not allowed to operate; individuals with certain health conditions were prioritized for testing and now vaccination. Demographic data were widely used to aid in this decision-making, justifying the costs and effort involved in collecting these data and setting the stage for future investments in data collection.

Sonalde Desai, Department of Sociology, University of Maryland and National Council of Applied Economic Research, New Delhi. 
The Indian government was surprised when, immediately following the lockdown, thousands of migrants from metropolitan cities began walking back to their hometowns, carrying the disease with them. As the government started looking for data on the number of rural migrants living in urban areas and their communities of origin and destination, it was discovered that migration data in India are minimal. It would be surprising if, in a post-pandemic world, data collection in India does not emphasize collecting more information about migrants and their living conditions. Similarly, given the greater vulnerability of individuals with preexisting health conditions to SAR-CoV-2, most countries have recognized the need for collecting information about disease prevalence. This interest in disease prevalence may well translate into a greater emphasis on collecting biomarkers, increasingly a staple of demographic surveys.

While the need for data has been high during the pandemic, collecting new data has been very difficult. As a result, investments in diverse research methodologies, particularly those that do not require face-to-face contact, have grown. While telephone surveys have emerged as a method of choice, web-based surveys and other modes of data collection such as GPS locationbased surveys of social interaction are beginning to play an important role in providing data. The multinational Facebook Covid Symptom Study, with millions of participants, provides an exciting example. Over the coming decade, data collected through these nontraditional sources will be subjected to greater scrutiny for reliability and representativeness, setting off a minor industry.

If the pandemic is likely to offer an increased emphasis on what Kreager (2015, p. S34) terms "Demography in Service of the State" through its data-collection arm, self-reflexive demographers might wonder whether demographic contributions to the public discourse, beyond the data we collect, lived up to its mark.

The pandemic highlighted topics that fall squarely within our domain-population mobility and social interaction; age, gender, and social class-specific prevalence of health risks such as cardiovascular conditions and diabetes; labor-force participation and nature of work; poverty and economic vulnerability. While many disciplines address one of these topics, the multidisciplinary nature of demography created a potential for us to integrate all of these considerations, thereby offering powerful tools for policy analysis that can be made locally specific. Sadly, this integration did not take place because it required different disciplines to work together. Although demography is multidisciplinary in its organization, true interdisciplinarity is harder to achieve, which may have limited demography's contributions to public policy at this critical time.

Demographic research through decades, most recently reflected in work by Case and Deaton (2020), shows that poverty is a leading cause of disease 
and death. If lockdowns minimize the spread of the pandemic and reduce income, should we not have tried to integrate considerations of health and mortality impacts of poverty and unemployment in our decision matrix through a feedback loop? Epidemiological models were remarkably silent about this feedback.

Social assistance benefits offered during the pandemic have been mostly agnostic regarding what demographers know about life-cycle forces that push people in and out of poverty and how they vary across countries. For example, demographic studies have consistently highlighted the vulnerability of single-parent families to external shocks. Single parents deprived of childcare may be more likely to fall into poverty. Occupational sex segregation often results in a disproportionate concentration of women in hospitality and retail sales. Thus, demographic insights would suggest that mother-headed families are more likely to be vulnerable to the pandemic's economic shocks. However, these insights have not been incorporated into the design and delivery of safety nets in the context of the pandemic.

How do we explain this exclusion of demographic insights from the policy discourse? Paul Demeny argued, "social science research directed to the developing countries in the field of population has now become almost exclusively harnessed to serve the narrowly conceived short-term interests of programs that embody existing orthodoxy in international population policy. In such a role, the contributions of research to social betterment are at best marginal" (Demeny 1988, p. 472).

Demeny's words, written over three decades ago, were surprisingly prescient. As of December 2020, the webpage on Covid-19 at the website of the International Union for the Scientific Study of the Population (IUSSP 2021) shows a substantial number of articles on the use of demographic data in estimating Covid-related mortality and a few items on the potentially negative impact of the pandemic on women. Yet, issues that have preoccupied governments worldwide as they seek to regulate movement across national and subnational boundaries, grapple with appropriate timing for imposing and reducing restrictions on economic activities, and provide subsidies, income transfers, and food aid to their populations are remarkable in their absence from this page.

I fully anticipate that this omission will be redressed in decades to come. Demographers will focus on the natural experiment that the pandemic offers to look at the impact of this year out of time on different cohorts and different life-cycle events. Researchers will focus on a range of topics such as comparison of learning outcomes between children experiencing distance education in primary school compared to that in secondary school, the impact of entering the labor market in 2020 vis-à-vis in earlier years, differential gendered impact of school closure on men and women, and, long-term health implications of being infected by SARS-CoV-2. Nonetheless, our inability to 
integrate what we already know into evidence-based policy design has been limited, possibly because of the way our discipline is organized.

I hope that the field will reflect on these missed opportunities for contributing to the public good when our inputs were most needed. Demographers have great potential for engaging the world of policymaking, and not all of it is limited to family planning programs or maternal and child health. However, to contribute to diverse discourses, we need to see ourselves as full partners and contributors to public policy and not merely as producers of data consumed by others.

It would be a mistake to attribute the absence of demographers from policy responses surrounding the pandemic only to the disjunction between academic researchers and policy mavericks. Academic economists were actively engaged in grappling with the policy challenges presented by the pandemic, as a thoughtful statement by academic economists at the International Growth Centre (IGC) demonstrates (IGC 2020), making the omission of demographic insights from these responses even more puzzling.

How do we explain the muted nature of demography's response to the crisis? Perhaps answers to this puzzle lie in an article by Alberto Palloni articulating the DNA of the discipline. Palloni (2002, p. 36) termed demography a dependent discipline, noting "Research practice of demography is characterized by heavy incursions from outside...demographers are sophisticated consumers of theoretical products elaborated elsewhere....This is not an ideal set of conditions to generate accepted claims of scientific territory, academic assertiveness, or self-assurance even within nonacademic professional environments."

The multidisciplinary nature of demography masks our lack of assertiveness. Economists, sociologists, anthropologists, and political scientists attend the annual meeting of Population Association of America (PAA). Many scholars from these disciplines publish in demographic journals and demographers build on insights from these fields in their own work. Nonetheless, the core enterprise of demography remains isolated from these adjacent disciplines and demographers rarely make assertive statements about policy formulation outside of what we consider our traditional areas of expertise such as family planning and health policy. Lack of demographic inputs in the design of social policies in the wake of the pandemic was particularly jarring and became obvious only when policies failed or problems emerged, such as the plight of stranded migrants.

I hope that in years to come, demographers will adopt a more assertive stance when it comes to public policies and engage in genuinely interdisciplinary research and dialogue. Disciplinary training in neighboring disciplines like economics, political science, and sociology will be the norm and politics of policymaking. The role of evidence and data in this enterprise will become a required course in demographic training. This will allow demographic 
knowledge to be integrated in public policy domains hitherto reserved for other disciplines such as economic development or social protection policies. Most importantly, we will begin to enlarge areas we see as squarely within the domain of demography in our research and data collection, returning us to our roots in political arithmetic.

\section{References}

Case, A. and A. Deaton. 2020. Deaths of Despair and the Future of Capitalism. Princeton, NJ: Princeton University Press.

Demeny, P. 1988. "Social science and population policy," Population and Development Review 14(3): 451-479.

International Growth Centre (IGC). 2020. "IGC COVID-19 guidance note: Containment strategies and support for vulnerable households." Retrieved from https://www.theigc.org/ publication/covid-19-guidance/ on January 4, 2020.

International Union for the Scientific Study of Population (IUSSP). 2021. "Demographers' contributions to the understanding of the COVID-19 pandemic." Retrieved from https:// iussp.org/fr/node/11297 on January 4, 2020.

Kreager, P. 2015. "Population theory: A long view," Population Studies 69: S29-S37.

Palloni, A. 2002. "Rethinking the teaching of demography: New challenges and opportunities," Genus 58(3/4): 35-70. 